\title{
DO DECRETO AO CONTROLE DO PROCESSO PEDAGÓGICO: OS COORDENADORES PEDAGÓGICOS SOB A TUTELA DAS AVALIAÇÕES EXTERNAS
}

\author{
DEL DECRETO AL CONTROL DEL PROCESO PEDAGÓGICO: LOS \\ COORDINADORES PEDAGÓGICOS BAJO LA TUTELA DE LAS \\ EVALUACIONES EXTERNAS
}

\section{FROM DECREE TO CONTROL OF THE PEDAGOGIC PROCESS: PEDAGOGICAL COORDINATORS UNDER THE AUTHORITY OF EXTERNAL EVALUTIONS}

\author{
Osmar Hélio Alves ARAÚJO1 \\ Janine Marta Coelho RODRIGUES ${ }^{2}$ \\ Wilson Honorato ARAGÃ ${ }^{3}$
}

RESUMO: Este artigo discute o processo de responsabilização pelos resultados das avaliações externas posto aos gestores escolares e, principalmente, aos coordenadores pedagógicos, sujeitos desta pesquisa. Metodologicamente, a pesquisa empírica, com âncora na abordagem qualitativa, envolveu três coordenadoras pedagógicas da Rede Municipal de Ensino do município de Cruz, Ceará. Para a coleta de dados aplicou-se três entrevistas semiestruturadas. A análise dos dados foi realizada por meio da análise do discurso. A partir do estudo em questão verificou-se as interferências das avaliações externas no cotidiano escolar, haja vista que estas impedem que a escola se construa pela via da participação efetiva, da força e criatividade dos sujeitos que a compõe, assim como os coloca cotidianamente no contexto escolar sob a ditadura contínua da linha de produção desencadeada pelas avaliações. O trabalho apresenta a necessidade dos coordenadores e professores tornarem-se sujeitos com militância pedagógica, assim como fugirem da batuta das avaliações que impedem a mobilidade pedagógica e ocasionam o excesso de trabalho.

PALAVRAS-CHAVE: Coordenador pedagógico. Avaliações externas. Processo pedagógico.

RESUMEN: Este artigo discute el proceso de responsabilidad por los resultados de las evaluaciones externas puesto a los gestores escolares y, principalmente, a los

\footnotetext{
${ }^{1}$ Doutorando em Educação pela Universidade Federal da Paraíba (UFPB). Atualmente é professor da Universidade Regional do Cariri (URCA). Email: osmar.araujo@urca.br

${ }^{2}$ Doutora em Educação pela Universidade Federal do Rio Grande do Norte (UFRN). Atualmente é professora titular, Classe E, da Universidade Federal da Paraíba (UFPB), atuando na linha de Pesquisa de Politicas Educacionais do Programa de Pós-Graduação Mestrado e Doutorado. Email: jmcoelho@ig.com.br

3 Doutor em Educação pela Universidade Federal do Rio Grande do Norte (UFRN). Atualmente é professor Associado II da Universidade Federal da Paraíba, Diretor do Centro de Educação/UFPB (20132016).Email: wilsonaragao@hotmail.com
}

RIAEE - Revista Ibero-Americana de Estudos em Educação, v. 12, n. 2, p. 951-965, 2017.

E-ISSN: 1982-5587 
coordinadores pedagógicos, sujeto de esta investigación. Metodológicamente, la investigación empírica, basada en el enfoque cualitativo, ha involucrado tres coordinadoras pedagógicas de la Red Municipal de Enseñanza del municipio de Cruz, Ceará. Para la colecta de datos, han sido aplicadas tres entrevistas semiestructuradas. El análisis de los datos ha sido realizado por medio del análisis del discurso. Desde el estudio en cuestión, se ha verificado que las interferencias de las evaluaciones externas impiden que la escuela se construya por la vía de la participación efectiva, de la fuerza y creatividad de los sujetos que la componen, bien como les pone cuotidianamente en el contexto escolar bajo la dictadura continua de la línea de producción provocado por estas mismas evaluaciones. El trabajo presenta la necesidad de los coordinadores y profesores en convertirse en sujetos con militancia pedagógica, así como huyeren de la batuta de las evaluaciones que impiden la movilidad pedagógica y ocasionan el exceso de trabajo.

PALAVRAS-CLAVE: Coordinador pedagógico. Evaluaciones externas. Proceso pedagógico.

ABSTRACT: This article discusses the process of accountability for the results of the external evaluations laid on the school managers and, mainly, on the pedagogical coordinators, subjects of this research. Methodologically, the empirical research, based upon the qualitative approach, involved three pedagogical coordinators of the Municipal Education System of the municipality of Cruz, Ceará. To the data gathering, three semi-structured interviews were applied. The data analysis was made through the speech analysis. From the study in question, the interference of the external evaluation on the school routine was verified, since it prevents the school to build itself through the effective participation, the strength and creativity of the individuals that are part of it, as well as place them on a daily basis, in the school routine, under the steady dictatorship of the production line triggered by the said evaluations. This work presents the need for the coordinators and teachers to become individuals with pedagogical activism, as well as escape from the auspices of the evaluations that prevent the pedagogical mobility and create an excess of work.

KEYWORDS: Pedagogical Coordination. External evaluations. pedagogic process.

\section{Introdução}

Os coordenadores pedagógicos e professores, com uma atuação fincada no campo da pedagogia e da didática, devem reconstruir diariamente o processo pedagógico da escola, assim como as suas concepções teóricas acerca da educação, e, por consequência, reinterpretar a sua realidade e a forma de compreendê-la e transformá-la.

Cada coordenador desempenha seu papel à medida que ultrapassa as fronteiras que o separa das práticas docentes, por isso deve colocar-se ao lado dos professores e 
dos demais sujeitos que compõem o contexto escolar, pois a atuação dos coordenadores se concretiza à proporção que atuam de modo articulado com as práticas docentes.

Este estudo discute o processo de responsabilização pelos resultados das avaliações externas posta aos gestores escolares e, principalmente, aos coordenadores pedagógicos, sujeitos desta pesquisa, os quais assumem, perante tais avaliações, uma posição de servil que desemboca, na maioria das vezes, na padronização do processo pedagógico da sala de aula e da escola. Logo, este estudo sublinha as interferências das avaliações externas na organização pedagógica das escolas a partir dos depoimentos das coordenadoras pedagógicas e, por consequência, discute o motor que impulsiona, paulatinamente, essas avaliações a serem tomadas como referência quando se trata de averiguar a qualidade da educação.

Este texto se encontra organizado em três partes: na primeira, expõe-se o percurso metodológico percorrido no desenvolvimento desta pesquisa. Na segunda parte, discorre-se sobre as interferências das avaliações externas na dinamicidade do processo pedagógico da escola e, por último, apresenta-se alguns apontamentos considerando os achados da pesquisa.

\section{Caminho metodológico}

Metodologicamente, a pesquisa empírica, com âncora na abordagem qualitativa, envolveu três coordenadoras pedagógicas da Rede Municipal de Ensino do município de Cruz, Ceará, as quais serão aqui denominadas de Coordenadoras A, B e C. Os critérios que abalizaram a seleção das entrevistadas foram: possuir mais de cinco anos de experiência no magistério e, preferencialmente, mais de dois anos de atuação na função de coordenadora pedagógica.

Foram aplicadas três entrevistas semiestruturadas visando averiguar as implicações das avaliações no trabalho pedagógico dos coordenadores pedagógicos. No tocante à entrevista, Farias et al. (2010) enfatiza que o aludido procedimento viabiliza o diálogo intencional entre entrevistador e entrevistado, objetivando colher dados expostos na linguagem do depoente a respeito de um tema específico. Para a interpretação dos dados colhidos, apoiou-se nos recursos metodológicos da análise crítica do discurso (FAIRCLOUGH, 2016). 
Em relação às coordenadoras pedagógicas entrevistadas, é oportuno ressaltar que a coordenadora pedagógica A é graduada em Pedagogia, pós-graduada em Gestão, Coordenação, Planejamento e Avaliação Escolar, com sete anos de atuação no magistério e, aproximadamente, três anos de experiência como coordenadora pedagógica. A coordenadora pedagógica B é graduada em Biologia, pós-graduada em Ensino de Matemática, e em Gestão, Coordenação, Planejamento e Avaliação Escolar, com vinte e dois anos de atuação no magistério e, aproximadamente, três anos de experiência como coordenadora pedagógica. A coordenadora pedagógica $\mathrm{C}$ é graduada em Pedagogia, pós-graduada em Gestão, Coordenação, Planejamento e Avaliação Escolar, com dez anos de atuação no magistério e, aproximadamente, quatro anos de experiência como coordenadora pedagógica. No tocante às escolas que as mesmas atuam, ambas estão localizadas na zona rural do município de $\mathrm{Cruz}^{4}$ e oferecem da Educação Infantil ao Ensino Fundamental.

Para interpretação e análise dos dados do estudo, baseou-se nas investigações conduzidas por Lima (2007), Franco (2008, 2016), Farias (2010), Castro (2011), Almeida (2014), Freitas (2014), Libâneo (2014), Fairclough (2016) e Araújo e Ribeiro (2016), dentre outros autores/as, que têm contribuído com pesquisas e ensaios teóricos pertinentes às avaliações externas e às políticas de responsabilização dos seus resultados, assim como sobre as interferências desses mecanismos de controle e regulação sobre o processo pedagógico das escolas públicas.

\section{Os achados da pesquisa}

Tenho visto nas escolas, em que adentro para pesquisas, um quadro de autonomia perdida, perderam-na todos os envolvidos. A escola é formada por sujeitos calados, deprimidos, que se apropriam apenas de discursos alheios, manipuladores. Percebe-se na escola um panorama amorfo: todos cativos de um discurso que referenda o necessário fracasso da escola (FRANCO, 2008, p. 116).

As contribuições de Franco (2008) foram trazidas para este texto para indicar que não se pode esquecer que os reformadores empresarias da educação ${ }^{5}$, em sintonia

${ }^{4}$ Cruz é um município do estado do Ceará, Brasil. Localiza-se na microrregião do Litoral de Camocim e Acaraú, mesorregião do Noroeste Cearense. O município tem 22.887 habitantes (Censo IBGE - 2012) e 334 km². Foi criado em 14 de janeiro de 1985 após ser emancipado de Acaraú através de plebiscito. Disponível em: <https://cruzce.wordpress.com/pequeno-historico-de-cruz/>. Acesso em: 28 jan. 2017.

${ }^{5}$ Segundo Freitas (2014, p. 1109): "Corporate reformers - assim são chamados os reformadores empresariais da educação nos Estados Unidos, em termo criado pela pesquisadora americana Diane Ravitch (2011). Ele reflete uma coalizão entre políticos, mídia, empresários, empresas educacionais, institutos e fundações privadas e pesquisadores alinhados com a ideia de que o mercado e o modo de 
com as instituições de financiamento, dentre elas o Banco Mundial, tem, de maneira incansável, por meio dos mecanismos ou políticas de avaliação educacional, gerenciado o sistema educacional brasileiro ${ }^{6}$ por meio do controle, da política de responsabilização, assim como da produção de resultados conforme às exigências de qualidade arroladas pelo mercado.

Contemplamos na contemporaneidade o paradoxo das avaliações externas postas pelos reformadores empresariais da educação, que alimentam o ideal da solução para muitos dos problemas da educação, entretanto, além de não os alcançar, geram alguns novos problemas e entraves, como a indução da padronização do processo pedagógico da escola.

Nesse sentido, as avaliações externas podem devastar a dinamicidade da organização pedagógica da escola e, logo, faz-se necessário rechaçar as estruturas dominantes que não condizem para tal. Neste contexto, Freitas (2014a) adverte que:

$\mathrm{Na}$ atual disputa pela escola, os reformadores empresariais da educação ampliaram a função da avaliação externa e deram a ela um papel central na indução da padronização como forma de permitir o fortalecimento do controle não só sobre a cultura escolar, mas sobre as outras categorias do processo pedagógico, pelas quais se irradiam os efeitos da avaliação, definindo o dia a dia da escola (FREITAS, 2014a, p.1093).

Libâneo (2014) entra no debate enfatizando que a posição assumida pela avaliação, por meio da pressão dos exames nacionais e internacionais, fortaleceu a lógica de alinhamento da escola a determinadas concepções didáticas que julgávamos superadas, e tornou possível, ainda, a internacionalização das políticas públicas. Como decorrente desse aspecto, percebe-se que as avaliações externas, como estão configuradas, são, em grande parte, constituídas para uniformizar a organização pedagógica das escolas brasileiras. Em sintonia com esta reflexão, a Coordenadora A entrevistada afirma que:

organizar a iniciativa privada é uma proposta mais adequada para "consertar" a educação americana, do que as propostas feitas pelos educadores profissionais".

${ }^{6}$ Lima (2007, p. 20) explica que: “[...] os vários Sistemas Educacionais de diferentes países, [...], como é o caso do Brasil, passaram a desenvolver, por iniciativa própria, indução e/ou até imposição das agências internacionais, em especial as instituições de financiamento, mecanismos ou políticas de Avaliação Educacional dos seus sistemas de ensino. Tais sistemas de avaliação focalizavam, prioritariamente, a mensuração do rendimento escolar dos alunos, com o objetivo de diagnosticar o desempenho dos sistemas em função dos investimentos decorrentes dos empréstimos contraídos". 
São inúmeros os fatores das avaliações externas que interferem no nosso trabalho, que chegam até a prejudicar. Os nossos professores ficam sobrecarregados com tantas exigências, não têm tempo de pensar e acabam seguindo aquele padrão de questões, avaliações e, por mais que digam que é apenas sugestão, não é, os professores são cobrados a seguir as orientações da Secretaria da Educação em relação a essas avaliações (COORDENADORA A).

A partir deste posicionamento, compreende-se que é necessário aproximar essas avaliações da realidade das escolas e deixar que os gestores, coordenadores e professores possam participar ativamente, dando sua colaboração. É imprescindível, no entanto, o fortalecimento do processo pedagógico da escola, pois ele oportuniza aos coordenadores pedagógicos e professores (re)interpretar, compreender e transformar a realidade do contexto escolar, de maneira que eles não devem estar procurando megaprojetos ou sofisticados processos avaliativos advindos de fora da escola. Deve-se, sim, investir em trabalhos pedagógicos que foquem as práticas cotidianas e ações pedagógicas e que façam emergir bons e duradouros resultados, haja vista que a educação deve ser um processo que forma verdadeiros cidadãos, segundo as suas necessidades, condições e com presença ativa na (re)construção da sociedade.

Os resultados enormes e rápidos da elevação das médias de desempenho de boa parte dos alunos, propalados pela mídia, são, na maioria das vezes, creditados ao heroísmo de inúmeras formas de responsabilização e meritocracia a que são submetidos professores, alunos e gestores. Entretanto, buscar remendar alguns problemas da educação aderindo a atalhos, como o incentivo à elevação das médias de desempenho dos estudantes sem uma reflexão crítica, é catastrófico, pois os alunos devem ser ouvidos, olhados e instruídos em uma perspectiva pedagógica, de forma a compreender o sentido da educação como um processo que faz a transformação da sociedade vir à tona. Corroborando com essa discussão, Franco (2016) adverte que:

A esfera da reflexão, do diálogo e da crítica parece cada vez mais ausente das práticas educativas contemporâneas, as quais estão sendo substituídas por pacotes instrucionais prontos, cuja finalidade é, cada vez mais, preparar crianças e jovens para as avaliações externas, a fim de galgarem um lugar nos vestibulares universitários. A educação, rendendo-se à racionalidade econômica, não mais consegue dar conta de suas possibilidades de formação e humanização das pessoas (FRANCO, 2016, p. 538).

Considerando as contribuições da autora, reitera-se aqui que é preciso que se compreenda que a organização pedagógica da escola deve se pautar em uma perspectiva 
investigativa e reflexiva sobre o próprio processo, assim como deve ser um percurso permeado pelo espírito de coletividade, envolvendo todos os sujeitos da instituição escolar. Entretanto, na mesma linha de entendimento de Franco (2016), ressalta-se que nos últimos tempos, acompanha-se a propagação de programas educacionais camuflados de formação docente, com formulações proeminentes e eloquentes que trazem o currículo anexo e insistem em dizer ao professor quantas páginas devem ser lidas pelos alunos por semana, quantas palavras um estudante deve apresentar em uma redação e ler em um minuto, assim como quantas provas devem ser ministradas e a que intervalos de tempo. Como consequência, o professor vai enchendo os discentes de um falso saber. Na direção do exposto, a Coordenadora B entrevistada expõe que:

Então, as atividades dos alunos, os conteúdos programáticos, são voltados para as avaliações externas. São aplicados antes das avaliações, simulados, provinhas e têm as formações, assim como os alunos são classificados por níveis, por exemplo, do $6^{\circ}$ ao $9^{\circ}$ ano, a partir dos simulados, eles são classificados em crítico, muito crítico, ou no nível desejado. E os professores precisam sempre elaborar questões conforme os itens das avaliações, porém, muitas vezes, nós temos nossas ideias, os nossos conteúdos, mas não são trabalhados como nós gostaríamos porque já vem à cobrança para que trabalhemos as matrizes das avaliações externas (COORDENADORA B).

O depoimento da coordenadora elucida, entre outros pontos, o quanto a escola está atrasada e quantas dificuldades há a partir das interferências das avaliações no cotidiano escolar, pois, o assento monárquico e concentrado das avaliações externas impede que a escola se construa pela via da participação efetiva, da força e criatividade dos sujeitos que a compõe. Entretanto, quando coordenadores e professores tornam-se sujeitos com militância pedagógica, a escola se renova continuamente, amplia-se, e muitas experiências significativas acontecem. Por isso, como assinalam Araújo e Ribeiro (2016), faz-se necessário que os coordenadores e professores estejam imersos em um contexto de pesquisa, de modo que possam revisitar sua prática e fazer um contraponto entre a teoria e a prática e, por consequência, materializar uma reflexão crítica da prática na prática. Compreende-se, por consequente, que o investimento na formação docente é necessário e importante para a educação, mas, como nos mostra em seu artigo a professora Helena Freitas (2014b):

O trato de algumas questões que dizem respeito à necessária alteração das bases da educação escolar, demanda indicações claras de ações e 
políticas que contribuam para superar a seriação e fragmentação disciplinar, principalmente nos anos finais do ensino fundamental e no ensino médio; alterar as formas de organização e trabalho das crianças; construir a unidade metodológica no trato com $\mathrm{o}$ conhecimento; instituir o trabalho coletivo e interdisciplinar dos educadores; criar condições de auto-organização dos estudantes na gestão democrática da escola e de sua própria formação integral; organizar os professores por grupos de estudo, por coletivos de ciclos e/ou turmas/séries no espaço escolar; inserir a participação dos pais, da comunidade e dos movimentos sociais na vida da escola; democratizar as funções diretivas escolares; implementar a escola de educação integral e superar o atual Programa Mais Educação; reduzir o número de alunos por sala na educação básica; e reorganizar os currículos, atendendo às necessidades sociais, acompanhando o avanço técnico-científico contemporâneo e a luta contra a discriminação e a exclusão (FREITAS, 2014b, p. 430).

Nesta perspectiva, pode-se começar por uma formação, de fato, para e com os professores, bem como pela valorização das experiências docentes bem-sucedidas, da construção de uma escola inserida na realidade histórica brasileira. Nesse sentido, os coordenadores e professores precisam ser estimulados a fugir da batuta das avaliações que impedem, muitas vezes, a mobilidade pedagógica, assim como ocasionam excesso de trabalho para ambos.

Pesquisas recentes, de Freitas (2014), Almeida (2014) e Castro (2011), demonstram que a tirania das avaliações externas e suas inúmeras exigências colocam os gestores - e entre eles, os coordenadores pedagógicos - sob a tutela da ditadura contínua dessas avaliações, fazendo com que os gestores recorram às mesmas como categorias que norteiam todo o processo de ensino e aprendizagem, do começo ao fim, assim como visando encontrar soluções, das mais diversas, para os problemas que permeiam esses processos. Da mesma forma, os professores, diante das estruturas das avaliações externas, apresentam relutância, enquanto outros tendem a fechar-se, a estarem na defensiva da sua autonomia; alguns são tomados por sentimentos de impotência diante da esfera escolar que tem sua diversidade padronizada e diluída em mil questões inócuas, lacunosas e sem sentido.

Os depoimentos das coordenadoras evidenciam um sentimento que ressoa com muita seriedade e preocupação, pois o processo pedagógico da escola, sua cultura, cotidiano, aos poucos vai perdendo sua liberdade e possibilidade de experimentar e inventar o novo, conviver e interagir com o diferente, haja vista que as avaliações externas não interagem e convivem com os diferentes jeitos de aprendizagem. Assim, declaram as coordenadoras entrevistadas A e B: 
As avaliações externas interferem no nosso trabalho de coordenadoras, ao ponto que, muitas vezes, não trabalhamos com nossos professores aquilo que planejamos, pois somos mandadas, forçadas, a fazer um trabalho tendo como foco simplesmente essas avaliações. É como se não tivéssemos opinião própria, autonomia, porque temos que seguir, querendo ou não, as normas, regras, visando atingir as metas que são estabelecidas, é como se estivéssemos engessadas, coordenadoras $e$ professores (COORDENADORA A).

[...] focamos demais nas avaliações e acabamos esquecendo, abandonando o que realmente temos que fazer, que é o acompanhamento pedagógico. Enfim, procuramos seguir o sistema das avaliações externas, focando as habilidades e competências que os alunos precisam desenvolver ao ponto que se eles não atingem, corremos atrás, seja de qualquer forma, para que os alunos alcancem os melhores resultados (COORDENADORA B).

Com isso, percebe-se o quanto é evidente que as coordenadoras pedagógicas estão cotidianamente no contexto escolar sob a ditadura contínua das avaliações externas, pois enfrentam muitas dificuldades para construírem uma estrutura pedagógica autônoma, autêntica, assim como um espaço escolar para o exercício da coletividade e para a propagação dos valores humanos. Quem estuda a temática um pouco mais a fundo sabe que até os livros didáticos são deixados em segundo plano quando os alunos ainda não apresentam as habilidades e competências exigidas pelas avaliações externas. É inegável, por exemplo, a interferência das avaliações externas em muitos aspectos dos processos de ensino e aprendizagem, como por exemplo: nas disciplinas de Geografia, História, Ciência, entre outras, pois, como expõe a coordenadora B entrevistada:

Nós, coordenadoras, somos muito cobrados em relação aos resultados das avaliações externas e, por consequência, os professores também. Inclusive em Geografia, História, Ciência, nós não trabalhamos os conteúdos específicos destas disciplinas não, mas focamos no ensino da Língua Portuguesa e Matemática, haja vista que temos que trabalhar os modelos de questões, os modelos das avaliações. Por exemplo: dia de quarta-feira é aula de História, mas trabalhamos uns minutinhos e no restante da aula trabalhamos é o Português, mas isso não quer dizer que eu não posso usar um texto de História nas aulas de Português. O professor pode sim, mas adaptando para o modelo de questões das avaliações. Então, as avaliações externas estão fortemente presentes no nosso dia a dia, pois, tudo que nós, coordenadores, fazemos é focando os resultados das avaliações (COORDENADORA B). 
As considerações da coordenadora aglutinam-se às contribuições de Freitas (2014a) ao trazer à tona que:

Temos conhecimento de escolas inseridas em processos de responsabilização que usam o tempo das disciplinas de história e geografia para reforçar o domínio de leitura e matemática do aluno e, posteriormente, atribuem a todas estas disciplinas a mesma nota que o aluno tira em matemática ou leitura (FREITAS, 2014a, p. 1110).

É possível verificar que as coordenadoras parecem perceber a força das avaliações externas na concretude do seu trabalho e nas práticas pedagógicas dos professores. É como uma força que passa "por cima" de todos, ao mesmo tempo em que todos estão suscetíveis às suas influências e impactos. Todo o contexto escolar, no entanto, com toda sua cultura, constitui fenômeno vivo, dinâmico, que não tem como ser isolado numa visão única, separada, cartesiana, intelectualizada e sedimentada. Fazer isso é empobrecer o processo educativo, tendo em vista que o mesmo deve ser imbuído de diálogos e trocas culturais firmadas ao longo da história.

Vale pôr em destaque também a expansão sensacionalista do sistema de avaliação externa, pois, muito mais dos que as razões tradicionalmente evidenciadas para a expansão das avaliações externas, é a difusão dos seus resultados pela mídia que as fizeram expandir-se rapidamente. Quem estuda o sistema de avaliação externa do Brasil, em especial do Ceará, percebe este fato e as exigências postas aos gestores. O depoimento da coordenadora $\mathrm{C}$ entrevistada ilustra essa ideia ao enfatizar que: “[...] entre as avaliações externas que mais focamos na nossa escola está o $\operatorname{SPAECE}^{7}$ e a Provinha Brasil ${ }^{8}$. Entretanto, somos mais cobradas, por parte da Secretaria de Educação, pelo SPAECE". No rastro do exposto, fica a pergunta: o que se passa por trás das avaliações externas?

Com este questionamento, para avançar em nossa reflexão, temos de cavar mais fundo, visando realçar que os reformadores empresariais da educação estão convencidos de que precisam manter as rédeas do movimento cotidiano das escolas em mãos, e eles preocupam-se em:

${ }^{7}$ Sistema Permanente de Avaliação do Ensino do Ceará. Disponível em: http://www.spaece.caedufjf.net/o-programa/. Acesso: 21 set. 2015.

${ }^{8}$ Provinha Brasil, elaborada e distribuída pelo Inep, para todas as secretarias de educação municipais, estaduais e do Distrito Federal, visa investigar o desenvolvimento das habilidades relativas à alfabetização e ao letramento em Língua Portuguesa e Matemática, desenvolvidas pelas crianças matriculadas no $2^{\circ}$ ano do ensino fundamental das escolas públicas brasileiras. Disponível em: <http://portal.inep.gov.br/web/provinha-brasil>. Acesso: 11 jul. 2016. 
1) Definir objetivos claros (o piano sobe ou desce?); 2) quantificar as metas (sem medir não sabemos onde estamos); 3) compartilhar as metas com os colaboradores; 4) criar instrumentos para acompanhar o funcionamento, passo a passo; e 5) criar mecanismos para premiar, punir e corrigir os desvios (FREITAS, 2014a, p. 1094).

Partindo das reflexões já suscitadas, estão patentes os impactos das avaliações externas na organização pedagógica das escolas, pois as avaliações não deixam por menos e exercem uma pressão considerável sobre os gestores, coordenadores e professores que, para não entrarem em choque com o "extraordinário desenvolvimento da qualidade da educação" e a qualquer momento serem chamados para interrogatórios vexatórios, rendem-se humildemente à pressão crescente dessas avaliações.

Logo, os gestores, coordenadores e muitos professores buscam, reiteradas vezes, modos, meios na perspectiva de emparelhar-se à linha de produção cravada pelos reformadores empresariais, ou seja, como apresentar os melhores resultados, haja vista "[...] que, se atingidos, autorizam recompensas definidas e contingentes aos índices (recompensas sociais e financeiras)." (FREITAS, 2014a, p. 1093). Segundo o mesmo autor, a função dos gestores converte-se em ser "[...] um animador que controla metas previamente 'comunicadas aos colaboradores' com processos bem definidos e controlados 'passo a passo', de forma a 'premiar, punir e corrigir desvios" (FREITAS, 2014a, p. 1093). Logo, isso é bastante para assinalar-se que os gestores, entre eles os coordenadores pedagógicos, vivem sob a batuta das avaliações externas. A expressão soa mal, porém, se não atingirem as metas estabelecidas pelas matrizes de referência das avaliações externas, dirão que seus alunos apresentam nível de proficiência insuficiente $^{9}$, ou seja, por consequência, percebe-se, de fato, o funcionamento da escola sob a pressão tácita da linha de produção dos reformadores empresariais da educação.

Finalizando, com esteio nas reflexões já suscitadas, verifica-se que, se os coordenadores aceitam e endossam a função das avaliações externas como estão postas, pela tirania da linha de produção, arriscam-se a isolar-se de sua própria realidade. Isso significa que a sobrevivência da instituição escolar, diante dos interesses dominantes, depende da sua carga de produção. Dito em outras palavras, a instituição escolar, da maneira como está funcionando concretamente, tem de ser considerada uma criação dos mecanismos concorrenciais dos reformadores empresariais da educação. Para os

${ }^{9}$ De acordo com a distribuição dos alunos por nível de proficiência, estar no nível Insuficiente significa apresentar pouquíssimo aprendizado, ou seja, é necessário a recuperação de conteúdos. Disponível em: http://www.qedu.org.br/brasil/proficiencia Acesso em: 10 de julho de 2016. 
gestores, não é tão fácil aceitar isso, mas não há como fugir da evidência. Inclusive, essas mesmas avaliações lhes conferem recompensas sociais e financeiras, sustentam financeiramente a hierarquia e lhes conferem prestígio e honorabilidade. Aceitar essa dependência estrutural exige uma boa dose de humildade por parte dos gestores, coordenadores e professores.

Talvez no futuro, com o avanço dos estudos críticos acerca dos impactos negativos e depreciativos das avaliações externas nos processos de ensino e aprendizagem, será mais fácil aceitar esta verdade: os interesses dos reformadores empresariais da educação e a função política-pedagógica da escola não se articulam bem. A partir dessa compreensão, a afirmação "os processos de ensino e aprendizagem e, por consequência, os sujeitos que compõem a instituição escolar, estão continuamente sob a ditadura contínua das avaliações externas", hoje tão controvertida, um dia será aceita como uma evidência.

\section{Considerações Finais}

Este texto buscou, desde as primeiras palavras, enaltecer a necessidade que os coordenadores pedagógicos desempenhem, de fato, na esfera escolar, um trabalho didático-pedagógico, livres de coações e tiranias postas pelos sistemas dos reformadores empresariais da educação. Nesta perspectiva, este trabalho quebra uma lança a favor da ação persistente e modesta de muitos coordenadores que não embarcam em grandes projetos, que não participam de sucessivos levantes a favor da padronização do processo pedagógico da escola, ao contrário, preferem projetos concretos e coadunados à sua realidade institucional.

A fundamentação que deve dar sentido ao trabalho dos coordenadores pedagógicos devem ser os campos da pedagogia e da didática, entre outros, assim como para todo o processo de formação contínua dos docentes, os quais, cada vez mais, devem buscar novas formas de oportunizar a atualização da organização pedagógica da escola. Nesta perspectiva, os coordenadores pedagógicos devem reunir a população docente com o intuito de discutir os caminhos, os desafios e os meios mais coerentes para a reconstrução das práticas pedagógicas no contexto escolar, entretanto, devem ser conscientes que necessitam (re)construir seu trabalho à luz do seu contexto de atuação e 
das suas próprias reflexões abalizadas na pedagogia, enquanto ciência que investiga o fenômeno educativo.

Os coordenadores pedagógicos, todavia, não constroem suas práticas de modo individual, pois sua atuação está profundamente enraizada em cada ação docente que também é construída no contexto escolar, ou seja, o exercício profissional dos coordenadores deve ser marcado pela autêntica presença dos professores, o que exige dos coordenadores abrir-se humildemente para aprender com quem poderia achar que não tem nada a ensinar.

\section{Referências}

ARAÚJO, Osmar Hélio.; RIBEIRO, Alves e Luís Távora Furtado. A didática e a pedagogia como suporte teórico para uma coordenação pedagógica qualificada. Revista online de Política e Gestão Educacional, Araraquara, v. 20, n. 2, p. 501-513, 2016. Disponível em: <http://dx.doi.org/10.22633/rpge.v20.n3.9533>. ISSN: 1519-9029.

ALMEIDA, L. C. Relação entre o desempenho escolar de escolas municipais de Campinas e o entorno da escola: a voz dos sujeitos. 2014. Tese (Doutorado em Educação), Faculdade de Educação - UNICAMP, Campinas, (2014).

CASTRO, C. M. Escola é empresa? O Estado de São Paulo. Sessão Opinião. 28 de setembro de 2011. Disponível em: <http://opiniao.estadao.com.br/noticias/geral,escolae-empresa-imp-,778472>. Acesso em: 12 Nov. 2015.

FAIRCLOUGH, Norman. Discurso e mudança social. 2a ed. Brasília: Editora UnB, 2016.

FARIAS, I. M. S. et al. Trilhas do labirinto na pesquisa educacional qualitativa: dos procedimentos de coleta de dados ao trabalho de campo. In: FARIAS, I. M. S. et al (Org.) Pesquisa científica para iniciantes: caminhando no labirinto. Fortaleza: EdUECE, 2010. p.10-18 - (Fundamentos da Pesquisa; v. 1. Coleção Métodos de Pesquisa).

FRANCO, Maria Amélia Santoro. Entre a lógica da formação e a lógica das práticas: a mediação dos saberes pedagógicos. Educação e Pesquisa, São Paulo, v. 34, n. 1, p. 109-126, jan./abr. 2008. Disponível em:

<http://www.revistas.usp.br/ep/article/view/28079 >. Acesso em: 09 fev. 2017.

FRANCO, Maria Amélia Santoro. Prática pedagógica e docência: um olhar a partir da epistemologia do conceito. Rev. bras. Estud. pedagog. (on-line), Brasília, v. 97, n. 247, p. 534-551, set./dez. 2016. Disponível em:

<http://www.scielo.br/pdf/rbeped/v97n247/2176-6681-rbeped-97-247-00534.pdf>.

Acesso em: 08 fev. 2017. 
FREITAS, Luiz Carlos de. OS REFORMADORES EMPRESARIAIS DA EDUCAÇÃO E A DISPUTA PELO CONTROLE DO PROCESSO PEDAGÓGICO NA ESCOLA. Educ. Soc., Campinas, v. 35, nº. 129, p. 1085-1114, out.-dez., 2014a. Disponível em: <http://www.scielo.br/pdf/es/v35n129/0101-7330-es-35-129-

01085.pdf >. Acesso em: 21 nov. 2016

FREITAS, Helena Costa Lopes de. PNE e formação de professores: Contradições e desafios. Revista Retratos da Escola, Brasília, v. 8, n. 15, p. 427-446, jul./dez. 2014b. Disponível em: <http//www.esforce.org.br>. Acesso em: 21 nov. 2015. Disponível em:< http://www.esforce.org.br/index.php/semestral/article/view/451/582>. Acesso em: 21 nov. 2016

LIBÂNEO, José Carlos. Internacionalização das políticas educacionais: elementos para uma análise pedagógica de orientações curriculares para o ensino fundamental e de propostas para a escola pública. In: SILVA, M. A.; CUNHA, C. D. Educação básica: políticas, avanços e pendências. Campinas: Autores Associados, 2014.

LIMA, Alessio Costa. O sistema permanente de avaliação da educação básica do Ceará (SPAECE) como expressão da política pública de avaliação educacional do estado. CE, 2007, 248f. Dissertação de Mestrado. (Mestrado Acadêmico em Políticas Públicas e Sociedade). Universidade Estadual do Ceará. Fortaleza, CE, 2007.

\section{Como referenciar este artigo:}

ARAÚJO, Osmar Hélio Alves.; RODRIGUES, Janine Marta Coelho.; ARAGÃO, Wilson Honorato. Do decreto ao controle do processo pedagógico: os coordenadores pedagógicos sob a tutela das avaliações externas. Revista Ibero-Americana de Estudos em Educação, Araraquara, v. 12, n. 2, p. 952-965, 2017. Disponível em: <http://dx.doi.org/10.21723/riaee.v12.n2.9827>. E-ISSN: 1982-5587.

Submetido em: 15/04/2017

Aprovação final em: 30/04/2017 